\title{
Variabilidade genética para características agronômicas em progênies de alface tolerantes ao calor
}

\author{
Maria da Conceição M de Souza'; Luciane V Resende'; Dimas Menezes'; Vivian Loges ${ }^{1}$; Tathiana A \\ Souto'; Venézio Felipe dos Santos ${ }^{2}$ \\ ${ }^{1}$ UFRPE-Dep ${ }^{\text {to. }}$ Agronomia, 52171-900 Recife-PE; ${ }^{2}$ IPA-EE Luiz Jorge da Gama Wanderley, 55600-000 Vitória de Santo Antão-PE; \\ luciane.vilela@ufla.br
}

\begin{abstract}
RESUMO
Avaliaram-se progênies de alface tolerantes ao pendoamento precoce quanto aos caracteres agronômicos desejáveis à comercialização, bem como estimaram-se componentes genéticos importantes para o melhoramento da cultura. O delineamento experimental utilizado foi blocos ao acaso, com três repetições e 18 tratamentos (13 progênies $\mathrm{F}_{7}$, os genitores Verdinha, Regina e Tinto, e as cultivares Luisa e Babá de Verão). Estimaram-se as variâncias genéticas, fenotípica e ambiental, as herdabilidades e as correlações entre os caracteres número de folhas, peso fresco da planta e das folhas, diâmetro da planta, comprimento do caule e pendoamento. $\mathrm{O}$ teste $\mathrm{F}$ foi significativo $(\mathrm{p}<0,01)$ para todas as características. No agrupamento das médias pelo teste Scott-Knott a 5\% de probabilidade, os tratamentos foram reunidos em dois grupos, exceto a cultivar Tinto, que se posicionou isoladamente em um terceiro grupo, para o caráter diâmetro da planta. A variância genética foi superior à ambiental para todas as características avaliadas e, a herdabilidade, inferior a $90 \%$, revelou a influência do ambiente para alguns caracteres. Quando se correlacionou pendoamento com as demais características, os resultados obtidos foram significativos e positivos para a maioria das combinações, considerando-se as correlações genéticas. Nas condições desse ensaio, a progênie 76, embora tenha apresentado desempenho comercial inferior às testemunhas, aos genitores e até mesmo a outras progênies, destacou-se para menor comprimento do caule e menor índice de pendoamento.
\end{abstract}

Palavras-chave: Lactuca sativa L., pendoamento precoce, herdabilidade, correlações genéticas.

\begin{abstract}
Genetic variability for agronomic characteristics in lettuce progenies with heat tolerance

Lettuce progenies with tolerance to early bolting were evaluated in relation to commercially desirable agronomic characters, as well as to estimate important genetic components for crop breeding. The experimental design was random blocks with three replications and 18 treatments (13 progenies $\mathrm{F}_{7}$, the genitors Verdinha, Regina, and Tinto, and cultivars Luisa and Babá de Verão). The genetic, phenotypic, and environmental variances, the heritability, and the correlation among the characters number of leaves, plant and leaves fresh weight, plant diameter, stem length, and bolting, were estimated. The $\mathrm{F}$ test was significant $(\mathrm{p}<0,01)$ for all the studied characteristics. In the clustering of means by the Scott-Knott test, at 5\% probability, treatments were assembled in two groups, except for plant diameter, in which cultivar Tinto remained isolated in a third group. The genetic variance was higher than the environmental variance for all evaluated characteristics, and the heritability, below $90 \%$, revealed the environmental influence over some characters. When bolting was correlated to the other characteristics, results were positive and significant for most combinations, considering the genetic correlations. Under these experimental conditions, progeny 76 stood out for its low stem length and reduced bolting index, although its commercial performance was inferior to the control cultivars, genitors, and some other progenies.
\end{abstract}

Keywords: Lactuca sativa L., bolting, heritability, genetic correlations.

\section{(Recebido para publicação em 24 de setembro de 2007; aceito em 12 de agosto de 2008)}

$\mathrm{D}$ entre as hortaliças folhosas, a alface é uma das mais consumidas e cultivadas no país, bem como no Nordeste brasileiro. Devido à alta perecibilidade e pouca resistência ao transporte, geralmente é cultivada próximo dos centros urbanos. Além das doenças, uma das limitações ao cultivo dessa hortaliça em regiões tropicais são as elevadas temperaturas. Caracterizase como uma espécie de clima temperado, sendo a temperatura o fator ambiental que mais influencia a formação de folhas e de cabeças de qualidade (Whitaker \& Ryder, 1974). As temperaturas ideais para produção de folhas e cabeças de qualidade se situam em tor- no de 12 e $22^{\circ} \mathrm{C}$ (Cock et al., 2002; Filgueira, 2003), sendo que temperaturas superiores a $22^{\circ} \mathrm{C}$ favorecem o florescimento precoce, antecipando a colheita (Mota et al., 2003). O pendoamento precoce provoca o alongamento do caule, reduz o número de folhas, afeta a formação da cabeça comercial e estimula a produção de látex, o que torna o sabor da folha amargo (Cock et $a l ., 2002)$, resultando na colheita de plantas ainda pequenas, com menor peso e número de folhas, de má qualidade, não expressando portanto o seu máximo potencial genético (Santana et al., 2005).

Vários estudos têm sido realizados visando à elucidação da base genética do florescimento precoce em alface. Segundo Ryder (1985), o alelo para florescimento precoce em alface é parcialmente dominante, reduzindo o tempo de florescimento pela metade. Esse gene foi denominado de Early flowering (Ef). Ryder \& Milligan (2005) identificaram um segundo par de genes denominados $E f$ - 1 ef- 1 e $E f$-2ef-2. O gene $E f$ 1 é parcialmente dominante sobre $e f-1$, enquanto $E f$-2 é parcialmente dominante sobre $e f-2$, na presença de $E f-1$, mas recessivo no genótipo ef-1ef-1, estando relacionado quantitativamente ao fotoperíodo.

Além do pendoamento precoce, as altas temperaturas dificultam a absorção 
de alguns nutrientes, como o cálcio. A baixa absorção de cálcio em alface caracteriza-se pelo surgimento de necrose nas extremidades das folhas, conhecida como queima de bordas ou tip burn (Cock et al., 2002; Beninni et al., 2003). Esta deficiência se manifesta tanto em cultivos no campo quanto em sistema protegido.

É de suma importância para o melhoramento desta cultura, o estudo dos efeitos do ambiente, sobretudo da temperatura, sobre os caracteres agronômicos e a forma como esses afetam a qualidade do produto final. A estimação dos efeitos genéticos e ambientais sobre determinado caráter, bem como da herdabilidade e das correlações genéticas são de fundamental importância para o melhoramento de plantas (Cruz, 2005). A obtenção de estimativas dos componentes genéticos e fenotípicos possibilitam a tomada de decisões relacionadas com a escolha do método mais apropriado, bem como de quais características podem ser utilizadas para seleção nas etapas iniciais e avançadas de um programa (Rossmann, 2001). A existência de variabilidade, particularmente a de natureza genética, é essencial para a obtenção de genótipos superiores em gerações avançadas em programas de melhoramento originados por hibridação de germoplasma de interesse.

O melhoramento genético da alface no Brasil teve início na década de 60 , com o pesquisador Hiroshi Nagai, concentrando-se na obtenção de genótipos resistentes a doenças e ao calor (Melo \& Melo, 2003). Porém, as pesquisas foram implementadas, em sua maioria, para as necessidades da Região CentroSul, onde as temperaturas são mais amenas. No Nordeste brasileiro, nas áreas onde se cultiva alface, as temperaturas médias mensais com frequiência são superiores a $30^{\circ} \mathrm{C}$, podendo chegar, nas épocas mais quentes do ano, a $35,1^{\circ} \mathrm{C}$ de acordo com o Laboratório de Meteorologia do Estado de Pernambuco (LAMEPE/ITEP, 2006). Outra peculiaridade desta região, especificamente em relação ao consumo da alface, refere-se à coloração das folhas, cuja preferência é por folhas verde-escuras, ao contrário do Centro-Sul, onde as folhas mais claras são as mais procuradas. Sendo as- sim, há necessidade de desenvolvimento de programas de melhoramento de alface que sejam específicos para esta região.

Por conseguinte, desenvolveu-se o presente trabalho, que teve como objetivo principal avaliar progênies de alface quanto à tolerância ao pendoamento precoce, com base em caracteres agronômicos desejáveis à comercialização. Ademais, buscou-se estimar os componentes genéticos importantes para o melhoramento da cultura.

\section{MATERIAL E MÉTODOS}

O experimento foi implementado em condições de campo, de agosto a dezembro de 2005, na EE Luiz Jorge da Gama Wanderley, pertencente à IPA, localizada no município de Vitória de Santo Antão, na Mesorregião da Mata Pernambucana $\quad\left(08^{\circ} 08^{\prime} 00^{\prime \prime} \mathrm{S}\right.$, $35^{\circ} 22^{\prime} 00^{\prime}$ 'W, altitude média de $146 \mathrm{~m}$ ) (Encarnação, 1980). Neste período, as médias mensais das temperaturas mínimas e máximas variaram entre 20,4 e $29,4^{\circ} \mathrm{C}$ (agosto) e 21,5 e $34^{\circ} \mathrm{C}$ (novembro), respectivamente, para mínimas e máximas (LAMEPE/ITEP, 2006).

Foram utilizadas 13 progênies $\mathrm{F}_{7}$ $(41 ; 44 ; 47 ; 53 ; 62 ; 66 ; 69 ; 73 ; 76 ; 78$; 84; 85 e 89), oriundas do cruzamento (Regina $x$ Tinto) x Verdinha, os genitores e, como testemunhas, as cultivares Luisa e Babá de Verão. A cultivar Verdinha apresenta folhas lisas com ondulações, soltas, verde-escuras, pouco tenras e relativamente espessas, com adaptação a altas temperaturas; a cultivar Regina possui folhas lisas de coloração verde-clara, tenras e suculentas; a cultivar Tinto possui folhas lisas, verde-claras, com cabeça pequena e é resistente ao vírus do vira-cabeça; a cultivar Luisa possui folhas lisas de coloração verde-clara, não forma cabeça, sendo considerada resistente ao pendoamento precoce e, por último, a cultivar Babá de Verão apresenta folhas lisas, coloração verde claro brilhante e é levemente enrugada (Cock et al., 2002; Filgueira, 2003).

O delineamento experimental utilizado foi blocos ao acaso, com três repetições e 18 tratamentos. As mudas foram produzidas em bandejas de poliestireno com 128 células, utilizando-se substrato comercial. A semeadura ocorreu em $30 / 08 / 05$, sendo que 25 dias após, realizou-se o transplantio para o campo, em canteiros com um metro de largura e 10 metros de comprimento. Cada parcela foi composta por doze plantas, com espaçamento de $30 \times 30$ $\mathrm{cm}$ entre as plantas. Os tratos culturais foram realizados conforme as recomendações para o cultivo na região (Lyra Filho et al., 2001). As adubações foram efetuadas conforme recomendado por Cavalcanti (1998), para cultura de alface.

Por ocasião da colheita, 32 dias após o transplante, foram avaliadas as características, para todas as plantas da parcela: número de folhas por planta (NF) (contagem do número de folhas maiores que três $\mathrm{cm}$, partindo das folhas basais); diâmetro da planta (DP) (distâncias entre as margens opostas da planta, expressas em centímetros); peso fresco da planta (PFP) (aferido após o corte rente ao solo no ato da colheita com posterior descarte de folhas impróprias para a comercialização); peso fresco das folhas (PFF) (obtido em quilogramas após a contagem do número de folhas); comprimento do caule (CC) (medido em centímetros, após a retirada das folhas, considerando-se o corte feito na planta rente ao solo) e; pendoamento (PEND) (quantificado pela contagem do número de plantas com início do desenvolvimento do pendão floral, por ocasião da colheita).

As análises estatísticas foram realizadas com o auxílio do programa GENES (Cruz, 2006). Para as características número de folhas e número de plantas pendoadas, os dados foram transformados utilizando a equação $\sqrt{x+1}$. Estimaram-se as variâncias fenotípicas, genotípicas e ambientais; as correlações fenotípicas, genotípicas e ambientais entre médias de progênies; o coeficiente de variação genética e demais parâmetros genéticos (Cruz et al., 2004). As médias foram agrupadas pelo teste de Scott-Knott, ao nível de 5\% de probabilidade (Scott \& Knott, 1974).

\section{RESULTADOS E DISCUSSÃO}

$\mathrm{O}$ teste de $\mathrm{F}$ foi significativo $(\mathrm{p}<0,01)$ para todas as características 
Tabela 1. Características agronômicas de genitores, gerações avançadas e cultivares de alface na época da colheita (agronomic traits of lettuce genitors, advanced generations and cultivars at the harvest). Vitória de Santo Antão, IPA, 2006.

\begin{tabular}{lrrrrrr}
\hline \multirow{2}{*}{ Genótipos $^{2}$} & \multicolumn{6}{c}{ Características $^{1}$} \\
\cline { 2 - 7 } & NF & PFP (g) & DP (cm) & PFF (g) & CC (cm) & PEND \\
\hline 41 & $35,0 \mathrm{~B}$ & $330 \mathrm{~A}$ & $15,9 \mathrm{~A}$ & $257 \mathrm{~A}$ & $8,93 \mathrm{~A}$ & $2,37 \mathrm{~A}$ \\
44 & $38,5 \mathrm{~A}$ & $380 \mathrm{~A}$ & $16,6 \mathrm{~A}$ & $317 \mathrm{~A}$ & $9,07 \mathrm{~A}$ & $1,67 \mathrm{~B}$ \\
57 & $39,0 \mathrm{~A}$ & $303 \mathrm{~A}$ & $14,4 \mathrm{~B}$ & $253 \mathrm{~A}$ & $5,23 \mathrm{~B}$ & $1,47 \mathrm{~B}$ \\
62 & $33,7 \mathrm{~B}$ & $203 \mathrm{~B}$ & $13,5 \mathrm{~B}$ & $187 \mathrm{~B}$ & $4,73 \mathrm{~B}$ & $1,66 \mathrm{~B}$ \\
66 & $36,6 \mathrm{~A}$ & $300 \mathrm{~A}$ & $14,0 \mathrm{~B}$ & $247 \mathrm{~A}$ & $6,49 \mathrm{~B}$ & $1,91 \mathrm{~B}$ \\
69 & $36,9 \mathrm{~B}$ & $247 \mathrm{~B}$ & $14,0 \mathrm{~B}$ & $180 \mathrm{~B}$ & $5,64 \mathrm{~B}$ & $1,75 \mathrm{~B}$ \\
73 & $36,8 \mathrm{~B}$ & $313 \mathrm{~A}$ & $15,9 \mathrm{~A}$ & $250 \mathrm{~A}$ & $8,87 \mathrm{~A}$ & $2,67 \mathrm{~A}$ \\
76 & $41,6 \mathrm{~A}$ & $267 \mathrm{~B}$ & $13,9 \mathrm{~B}$ & $240 \mathrm{~A}$ & $6,44 \mathrm{~B}$ & $1,14 \mathrm{~B}$ \\
78 & $38,2 \mathrm{~A}$ & $223 \mathrm{~B}$ & $13,5 \mathrm{~B}$ & $200 \mathrm{~B}$ & $3,44 \mathrm{~B}$ & $1,00 \mathrm{~B}$ \\
84 & $38,3 \mathrm{~A}$ & $370 \mathrm{~A}$ & $15,1 \mathrm{~A}$ & $297 \mathrm{~A}$ & $8,27 \mathrm{~A}$ & $1,82 \mathrm{~B}$ \\
85 & $31,2 \mathrm{~B}$ & $307 \mathrm{~A}$ & $14,9 \mathrm{~B}$ & $270 \mathrm{~A}$ & $6,87 \mathrm{~B}$ & $2,43 \mathrm{~A}$ \\
89 & $41,0 \mathrm{~A}$ & $247 \mathrm{~B}$ & $13,4 \mathrm{~B}$ & $213 \mathrm{~B}$ & $4,74 \mathrm{~B}$ & $1,55 \mathrm{~B}$ \\
Verdinha & $38,6 \mathrm{~A}$ & $307 \mathrm{~A}$ & $14,8 \mathrm{~B}$ & $227 \mathrm{~B}$ & $7,06 \mathrm{~B}$ & $1,63 \mathrm{~B}$ \\
Regina & $42,7 \mathrm{~A}$ & $331 \mathrm{~A}$ & $14,8 \mathrm{~B}$ & $269 \mathrm{~A}$ & $9,94 \mathrm{~A}$ & $2,95 \mathrm{~A}$ \\
Tinto & $42,9 \mathrm{~A}$ & $334 \mathrm{~A}$ & $14,1 \mathrm{~B}$ & $255 \mathrm{~A}$ & $6,32 \mathrm{~B}$ & $1,14 \mathrm{~B}$ \\
Luisa & $34,4 \mathrm{~B}$ & $147 \mathrm{~B}$ & $10,7 \mathrm{C}$ & $188 \mathrm{~B}$ & $6,06 \mathrm{~B}$ & $1,24 \mathrm{~B}$ \\
Babá de Verão & $39,0 \mathrm{~A}$ & $288 \mathrm{~A}$ & $16,6 \mathrm{~A}$ & $245 \mathrm{~A}$ & $5,68 \mathrm{~B}$ & $1,38 \mathrm{~B}$ \\
CV (\%) & $39,1 \mathrm{~A}$ & $273 \mathrm{~B}$ & $14,4 \mathrm{~B}$ & $216 \mathrm{~B}$ & $8,43 \mathrm{~A}$ & $2,44 \mathrm{~A}$ \\
\hline & 5,27 & 14,534 & 5,39 & 17,11 & 25,97 & 31,58 \\
\hline
\end{tabular}

Médias seguidas pela mesma letra nas colunas não diferem entre si, teste de Scott-Knott, $\mathrm{p}<0,05$ (Means followed by the same letter in the column did not differ from each other, Scott-Knott test, $\mathrm{p}<0.05$ ); ${ }^{1} \mathrm{NF}$ : número de folhas (number of leaves); PFP: peso fresco da planta (plant fresh weight); DP: diâmetro da planta (plant diameter); PFF: peso fresco das folhas (leaf fresh weight); CC: comprimento do caule (cm) e PEND: número de plantas pendoadas (number of plants with bolting); ${ }^{2} 41$ a 89: linhas recombinadas na geração $\mathrm{F}_{7}$ (inbred lines recombined in $\mathrm{F}_{7}$ ); genitores (genitors): Verdinha, Regina e Tinto; cultivarestestemunhas (Check cultivars): Luisa e Babá de Verão.

estudadas, demonstrando que os tratamentos diferiram significativamente entre si. Pelo teste Scott-Knott, a 5\% de probabilidade, houve a formação de pelo menos dois grupos para as características avaliadas (Tabela 1). Excetuou-se diâmetro da planta, em que a cultivar Tinto se posicionou isoladamente em um terceiro grupo.

Os coeficientes de variação experimental variaram de 5,27\%, para o caráter número de folhas, a $31,58 \%$ para número de plantas pendoadas. Porém neste ensaio, para a maioria dos caracteres avaliados, os coeficientes de variações experimentais foram considerados baixos, demonstrando uma boa precisão do experimento. Os coeficientes de variação expressos para diâmetro da planta e comprimento de caule foram de 5,39\% e 25,97\%, respectivamente. Valores próximos foram obtidos por Lédo et al. (2001) e Mota et al. (2003) para estes caracteres. Os maiores valo-
Considerando número de folhas, diâmetro da planta e peso fresco da planta como os caracteres agronômicos mais importantes para a comercialização, verificou-se que, respectivamente, $53,85 \%, 61,54 \%$ e $30,77 \%$ das progênies e os genitores Regina e Verdinha se posicionaram no grupo $\mathrm{A}$, revelando melhor desempenho (Tabela 1). Já para comprimento de caule, característica limitante da produção, as médias variaram no grupo A, de 8,43 cm (Babá de Verão) a 9,94 cm para a cultivar Verdinha, valores estes, considerados altos (Tabela 1). Os genótipos com os menores comprimentos de caule concentraram-se no grupo B, sendo o menor valor observado na progênie 76 , com $3,44 \mathrm{~cm}$ (Tabela 1). Além disso, esta foi a progênie que conteve o menor número de plantas pendoadas na colheita. Tem-se, pois, como destaque a progênie 76 , embora tenha revelado comportamento quanto a características comerciais um pouco inferior às testemunhas, aos genitores e até mesmo a outras progênies.

Em 53\% dos caracteres avaliados a variância genotípica foi superior à ambiental (Tabela 2). Esse grupo incluiu também os caracteres mais afetados pelo efeito do ambiente, como comprimento de caule e pendoamento. Isso resultou em valores elevados para herdabilidade. Silva et al. (1999) encontraram resultados semelhantes para pendoamento precoce em populações de alface tolerantes ao calor. Por meio destes resultados, torna-se real a possibilidade de ganhos expressivos na seleção de progênies, o que é corroborado pelas estimativas das razões entre os coeficientes de variação genética e experimental $\left(\mathrm{CV}_{\mathrm{G}} / \mathrm{CV}_{\mathrm{E}}\right)$, que expressaram valores próximos ou superiores à unidade.

Quando se correlacionou o pendoamento com as demais características, os resultados obtidos foram significativos e positivos para a maioria das combinações, considerando as correlações genéticas (Tabela 3). Correlações genotípicas e fenotípicas com sinais contrários foram observadas quando se correlacionou número de folhas e comprimento de caule, demonstrando, conforme Falconer (1987), que as causas da variação genética e ambiental in- 
fluenciam estas características por meio de mecanismos fisiológicos diferentes.

Observou-se que à medida que ocorre a emissão do pendão floral, há uma redução do número de folhas. $\mathrm{O}$ fato destas duas características se correlacionarem negativamente $\left(r_{G}=-0,0337\right)$, indica certa dificuldade na seleção de progênies para maior número de folhas e ausência de pendoamento nesta população. Ainda considerando a característica pendoamento, o maior valor de correlação genotípica foi obtido para comprimento de caule e peso fresco das folhas. Foram observadas correlações genéticas positivas com as demais características: peso fresco da planta $(0,5364)$, diâmetro da planta $(0,5565)$, peso fresco das folhas $(0,5979)$. Estes resultados denotam que maiores valores para os caracteres mais importantes agronomicamente como, diâmetro da planta e peso fresco de plantas, podem ser obtidos quando se reduzir a emissão do pendão floral.

O peso fresco das folhas e o peso fresco da planta revelaram correlação genotípica de 0,96, demonstrando que em futuras seleções é interessante utilizar outras características como critério de seleção. Oliveira et al. (2004), avaliando o descarte de características em alface para cultivo em sistema hidropônico, verificaram índices de correlações genotípicas muito elevados entre peso fresco e seco de raiz, peso fresco de raiz e comprimento do caule, peso fresco e seco de planta e, entre peso fresco e seco do caule, enfatizando que nos futuros programas de melhoramento a utilização de características como peso seco de folhas e de plantas, é menos interessante do que as características peso fresco de folhas e peso fresco de planta, em face da alta correlação genotípica detectada.

Embora sejam progênies avançadas $\left(\mathrm{F}_{7}\right)$, ainda é possível efetuar seleção para os caracteres avaliados em função da variabilidade observada, tanto dentro quanto entre progênies, em especial se a seleção se destinar a outros sistemas de cultivo.

\section{AGRADECIMENTOS}

A UFRPE e ao IPA, pelo apoio dado para a condução do experimento, e ao CNPq e à FACEPE, pela concessão de recursos financeiros destinados a realização desse trabalho.

Tabela 2. Estimativas de parâmetros genéticos para características morfoagronômicas avaliadas em $13 \mathrm{~F}_{7}$ linhas endogâmicas recombinadas de alface (estimates of genetic parameters for morphoagronomic traits evaluated in 13 lettuce $\mathrm{F}_{7}$ recombinant inbred lines). Vitória de Santo Antão, IPA, 2006.

\begin{tabular}{lcccccc}
\hline \multirow{2}{*}{ Parâmetros } & \multicolumn{7}{c}{ Características $^{1}$} \\
\cline { 2 - 7 } & NF & PFP & DP & PFF & CC & PEND \\
\hline$\sigma_{P}^{2}$ & 8,070 & 0,003 & 1,081 & 0,002 & 3,215 & 0,322 \\
$\sigma_{E}^{2}$ & 1,291 & 0,000 & 0,207 & 0,001 & 1,036 & 0,107 \\
$\sigma_{G}^{2}$ & 6,777 & 0,002 & 0,874 & 0,001 & 2,179 & 0,216 \\
$h_{r}^{2}(\%)$ & 83,99 & 78,79 & 80,82 & 64,85 & 67,77 & 66,94 \\
$\mathrm{CV}_{\mathrm{G}}(\%)$ & 6,97 & 16,10 & 6,39 & 13,45 & 21,74 & 25,94 \\
$\mathrm{CV}_{\mathrm{G}} / \mathrm{CV}$ & 1,32 & 1,11 & 1,18 & 0,79 & 0,83 & 0,82 \\
\hline
\end{tabular}

${ }^{1} \mathrm{NF}$ : número de folhas (number of leaves); PFP: peso fresco da planta (plant fresh weight); DP: diâmetro da planta (plant diameter); PFF: peso fresco das folhas (leaf fresh weight); CC: comprimento do caule (cm) e PEND: número de plantas pendoadas (number of plants with bolting); ${ }^{2} 41$ a 89: linhas recombinadas na geração $\mathrm{F}_{7}$ (inbred lines recombined in $\mathrm{F}_{7}$ ); genitores (genitors): Verdinha, Regina e Tinto; cultivares-testemunhas (Check cultivars): Luisa e Babá de Verão; ${ }^{2} \sigma_{F}^{2}$ : variância fenotípica (phenotypic variance); $\sigma_{E}^{2}$ : variância ambiental (environmental variance); $\sigma_{G}^{2}$ : variância genética (genetic variance); $h_{r}^{2}$ : coeficiente de herdabilidade no sentido restrito (heritability coefficient, narrow sense); $\mathrm{CV}_{\mathrm{G}}(\%)$ : coeficiente de variação genético (genetic coefficient of variation); $\mathrm{CV}_{\mathrm{E}}$ : coeficiente de variação ambiental (environmental coefficient of variation).

Tabela 3. Estimativas dos coeficientes de correlação genotípica $\left(\mathrm{r}_{\mathrm{G}}\right)$, fenotípica $\left(\mathrm{r}_{\mathrm{F}}\right)$ e ambiental $\left(r_{E}\right)$ entre caracteres agronômicos de progênies $F_{7}$ de alface. (estimates of phenotypic $\left(r_{F}\right)$, genotypic $\left(\mathrm{r}_{\mathrm{G}}\right)$, and environmental $\left(\mathrm{r}_{\mathrm{E}}\right)$ correlation coefficients between agronomic traits of lettuce $\mathrm{F}_{7}$ recombinant inbred lines). Vitória de Santo Antão, IPA, 2006.

\begin{tabular}{|c|c|c|c|c|c|c|}
\hline & \multirow{2}{*}{ Correlação } & \multicolumn{5}{|c|}{ Características $^{1}$} \\
\hline & & PFP & DP & PFF & CC & PEND \\
\hline & $r_{G}$ & $0,0547^{\text {ns }}$ & $0,3238^{\text {ns }}$ & $0,0652^{\text {ns }}$ & $-0,2056^{\mathrm{ns}}$ & $-0,0337^{\text {ns }}$ \\
\hline \multirow[t]{3}{*}{ NF } & $r_{F}$ & $0,0159^{\text {ns }}$ & $0,1863^{\text {ns }}$ & $0,0037^{\text {ns }}$ & $0,0881^{\text {ns }}$ & $-0,2320^{n s}$ \\
\hline & $r_{E}$ & $0,3278^{\text {ns }}$ & $0,4592^{\text {ns }}$ & $0,2184^{\text {ns }}$ & 0,8080 ** & $0,0022^{\text {ns }}$ \\
\hline & $r_{G}$ & & $0,8683^{* *}$ & $0,9591^{* *}$ & $0,6433^{*}$ & $0,5364^{\mathrm{ns}}$ \\
\hline \multirow[t]{3}{*}{ PFP } & $r_{F}$ & & 0,8589 ** & $0,9313^{* *}$ & $0,6571^{*}$ & $0,3796^{\text {ns }}$ \\
\hline & $r_{E}$ & & 0,8230 ** & $0,8999 *$ * & $0,7078^{* *}$ & $-0,0121^{\mathrm{ns}}$ \\
\hline & $r_{G}$ & & & $0,8152^{* *}$ & $0,4710^{\text {ns }}$ & $0,5565^{*}$ \\
\hline \multirow[t]{3}{*}{ DP } & $r_{F}$ & & & $0,7668^{* *}$ & $0,4953^{\text {ns }}$ & $0,4138^{\text {ns }}$ \\
\hline & $r_{E}$ & & & $0,6802^{* *}$ & $0,6223^{*}$ & $-0,0407^{\mathrm{ns}}$ \\
\hline & $r_{G}$ & & & & $0,5593^{*}$ & $0,5979^{*}$ \\
\hline \multirow[t]{3}{*}{ PFF } & $r_{F}$ & & & & $0,5747^{*}$ & $0,3722^{\text {ns }}$ \\
\hline & $r_{E}$ & & & & $0,6057^{*}$ & $-0,0202^{\text {ns }}$ \\
\hline & $r_{G}$ & & & & & $1,009^{* *}$ \\
\hline \multirow[t]{2}{*}{$\mathrm{CC}$} & $r_{F}$ & & & & & $0,7544^{* *}$ \\
\hline & $\mathrm{R}_{\mathrm{E}}$ & & & & & $-0,0317^{\mathrm{ns}}$ \\
\hline
\end{tabular}

*,**significativo a 5 e $1 \%$, pelo teste $\mathrm{t}$, respectivamente, e ns: não significativo (*,**significant, $\mathrm{t}$ test, $\mathrm{p}<0.05$ and $\mathrm{p}<0.01$, respectively; ns: not significant); ${ }^{2} \mathrm{NF}$ : número de folhas (number of leaves); PFP: peso fresco da planta (plant fresh weight); DP: diâmetro da planta (plant diameter); PFF: peso fresco das folhas (leaf fresh weight); CC: comprimento do caule (cm) e PEND: número de plantas pendoadas (number of plants with bolting).

\section{REFERÊNCIAS}

BENINNI ERY; TAKAHASHI HW; NEVES CSVJ. 2003. Manejo de cálcio em alface de cultivo hidropônico. Horticultura Brasileira 21: 605-610.
CAVALCANTI FJAC. 1998. Recomendação de adubação para o Estado de Pernambuco: $2^{\mathrm{a}}$ aproximação. Recife: IPA. 198p.

COCK WRS; AMARAL JUNIOR AT; BRESSAN-SMITH RE; MONNERAT PH. 2002. Biometrical analysis of phosphorus use efficiency in lettuce cultivars adapted to high temperatures. Euphytica 126: 299-308. 
CRUZ CD. 2005. Princípios de genética quantitativa. Viçosa: UFV. 394p.

CRUZ CD. 2006. Programa Genes: biometria. Viçosa: Imprensa Universitária, 480p.

CRUZ CD; REGAZZI AJ; CARNEIRO PCS. 2004. Modelos biométricos aplicados ao melhoramento genético. Viçosa: UFV. 480p.

ENCARNAÇÃO CRF. 1980. Observações meteorológicas e tipos climáticos das unidades e campos experimentais da Empresa IPA. Recife: IPA. 110p.

FALCONER DS. 1987. Introdução à genética quantitativa. Viçosa: UFV. 359p.

FILGUEIRA FAR. 2003. Novo manual de olericultura: agrotecnologia moderna na produção e comercialização de hortaliças. Viçosa: UFV. 412p.

GOMES FP. 1990. Curso de estatística experimental. 13 ed. Piracicaba: Nobel. 468p.

LAMEPE/ITEP - Laboratório de Meteorologia do Estado de Pernambuco/Instituto Tecnológico de Pernambuco. 2006, 13 de junho. Dados Meteorológicos - Vitória de Santo Antão-PE. Disponível em: http://www.agritempo.gov.br/ agroclima.

LÉDO FJS; CASALI VWD; CRUZ CD; LÉDO CAS. 2001. Análise genética em um dialelo de alface. Pesquisa Agropecuária Brasileira 369: 493-499.
LYRA FILHO HP; SÁ VAL; RODRIGUES VJLB; ANDRADE DEGT; TAVARES FILHO JJ; SILVA MCL. 2001. Avaliação de cultivares de alface para a zona da mata úmida de Pernambuco. In: CONGRESSO BRASILEIRO DE OLERICULTURA, 41. Resumos... Brasília: SOB (CD-ROM).

MELO AMT; MELO PCT. 2003. Hiroshi Nagai (1935-2003): sua vida e contribuições à olericultura. Horticultura Brasileira 21: 4.

MOTA JH; YURI JE; FREITAS SAC; RODRIGUES JUNIOR JC; RESENDE GM; SOUZA RJ. 2003. Avaliação de cultivares de alface americana durante o verão em Santana da Vargem, MG. Horticultura Brasileira 21: 234-237.

OLIVEIRA ACB; SEDYIAMA MAN; PEDROSA MW; GARCIA NCP; GARCIA SLR. 2004. Divergência genética e descarte de variáveis em alface cultivada sob sistema hidropônico. Acta Scientiarum Agronomy 26: 211-217.

RAMALHO MAP; FERREIRA DF; OLIVEIRA AC. 2000. Experimentação em genética e melhoramento de plantas. Lavras: UFLA. 326p.

ROSSMANN H. 2001. Estimativas de parâmetros genéticos e fenotípicos de uma população de soja avaliada em quatro anos. Piracicaba: USP-ESALQ. 80p (Tese doutorado).
RYDER EJ. 1985. Use of early flowering genes to reduce generation time in backcrossing, with specific application to lettuce breeding. The Journal of the American Society for Horticultural Science 110: 570-573.

RYDER EJ; MILLIGAN DC. 2005. Additional genes controlling flowering time in $L$. sativa and L. serriola. The Journal of the American Society for Horticultural Science 130: 448453.

SANTANA CVS; ALMEIDA AC; FRANÇA FS; TURCO SHN; DANTAS BF; ARAGÃO CA. 2005. Influência do sombreamento na produção de alface nas condições climáticas do semi-árido nordestino. In: CONGRESSO BRASILEIRO DE OLERICULTURA, 45. Resumos... Fortaleza: SOB (CD-ROM).

SCOTT AJ; KNOTT M. 1974. A cluster analysis method for grouping means in the analysis of variance. Biometrics 30: 507-512.

SILVA EC; MALUF WR; LEAL NR; GOMES LAA. 1999. Inheritance of bolting tendency in lettuce (Lactuca sativa L.). Euphytica 109: 1-7.

WAYCOTT W. 1995. Photoperiodic response of generally diverse lettuce accessions. The Journal of the American Society for Horticultural Science 120: 460-467.

WHITAKER TW; RYDER EJ. 1974. Lettuce production in the United States. Agriculture HandBook, 43p. 